\title{
Heat of Formation of Titanium Tetrabromide
}

\author{
Raymond A. Nelson, ${ }^{1}$ Walter H. Johnson, and Edward J. Prosen
}

\begin{abstract}
The heat of formation of solid titanium tetrabromide has been measured by the reaction of titanium metal with gaseous bromine in a calorimeter. The following value for the heat of reaction was obtained:

$$
\begin{gathered}
\operatorname{Ti}(\mathrm{c})+2 \mathrm{Br}_{2}(\mathrm{~g})=\mathrm{TiBr}_{4}(\mathrm{c}) \\
\triangle \mathrm{Hf}^{\circ}\left(25^{\circ} \mathrm{C}\right)=-678.16 \pm 4.60 \mathrm{kj} / \mathrm{mole}(-162.08 \pm 1.10 \mathrm{kcal} / \mathrm{mole}) .
\end{gathered}
$$

Combination of this value with the heat of vaporization of bromine yields the standard heat of formation of $\mathrm{TiBr}_{4}$ (c) from $\mathrm{Ti}(\mathrm{c})$ and $\mathrm{Br}_{2}$ (liq) as $\triangle \mathrm{Hf}^{\circ}\left(25^{\circ} \mathrm{C}\right)=-616.72 \pm 4.60 \mathrm{kj} /$ mole $(-147.40 \pm 1.10 \mathrm{kcal} / \mathrm{mole})$.
\end{abstract}

\section{Introduction}

Prior to this investigation the existing value for the heat of formation of titanium tetrabromide was that estimated by Brewer, Bromley, Gilles, and Lofgren [1] ${ }^{2}$, who gave $-170 \pm 10 \mathrm{kcal} /$ mole for the reaction of titanium with gaseous bromine. Their calculations were based on an old value for the heat of formation of titanium tetrachloride [2], and upon disproportionation studies and estimated heats of solution.

Rossini, Wagman, Evans, Levine, and Jaffe [3] give $-155 \mathrm{kcal} / \mathrm{mole}$ for the heat of formation of titanium tetrabromide; this value was obtained by combining the value estimated by Brewer et al., with the heat of vaporization of bromine.

The present investigation was undertaken to provide direct experimental data for the heat of formation of titanium tetrabromide.

\section{Source and Purity of Materials}

A sample of sponge titanium, obtained from the U. S. Bureau of Mines, was used for some of the preliminary experiments in this investigation. No information was available regarding the purity of this material except that it had a Brinell hardness of 136 .

A sample of commercial titanium sheet was used for other preliminary experiments. This sample was obtained from the Titanium Metals Corporation of America, who supplied the following analysis: 99.74 percent titanium, 0.019 percent carbon, 0.047 percent nitrogen, 0.08 percent iron, and 0.17 percent oxygen.

For the final measurements, the results of which are tabulated in this paper, we used a sample of titanium prepared at the Naval Research Laboratory by the thermal reduction of titanium tetraiodide. This sample was cut from the same material as that used for measurement of the heat of formation of the tetrachloride [4]; the purity of this sample was in excess of 99.99 percent.

Present address: U. S. Treasury Department, Alcohol Tax Unit, Washington 25, D. C.

2 Figures in brackets indicate the literature references at the end of this paper.
The bromine was taken from reagent grade material. A portion of the bromine was analyzed and found to contain 0.22 percent of chlorine, but the presence of iodine or of organic bromides was not detected. The effect of the chlorine is discussed in another section of this paper.

A mass spectrometric analysis of helium made by the Mass Spectrometry Section of the Atomic and Radiation Physics Division showed that the helium contained less than 0.01 percent of air. It was purified further by passing it over titanium metal at $600^{\circ} \mathrm{C}$, copper oxide at $600^{\circ} \mathrm{C}$, and through absorbers containing Ascarite, anhydrous magnesium perchlorate, and phosphorus pentoxide.

\section{Apparatus}

It was intended that the same calorimetric reaction vessel would be used for the experiments on titanium tetrabromide that was used for the tetrachloride [4]. However, since an operating temperature of $500^{\circ} \mathrm{C}$ was required, this vessel, which was designed for operation only up to $350^{\circ} \mathrm{C}$, was not suitable. It was decided, therefore, to use instead a vessel previously used for measurement of the heats of decomposition of diborane and pentaborane [5]. The titanium sample was placed between glass-wool plugs near the lower end of the quartz tube and was heated by the lower segment of the heating coil. A mixture of bromine and helium vapors entered the vessel at the bottom, passed over the hot sample and out through the glass helix.

The bromine was contained in an external bubbling vessel which was weighed before and after each experiment. Valves were provided in the gas train whereby purified helium could (a) be passed directly into the reaction vessel, (b) be saturated with bromine and passed into the reaction vessel, or (c) bypass both the bromine bubbler and the reaction vessel.

The exit gases were cooled to the temperature of the calorimeter in the glass helix; upon leaving the reaction vessel they passed through a trap cooled in liquid nitrogen, where the excess bromine and the traces of $\mathrm{TiBr}_{4}$ vapor were collected.

The calorimeter, thermometric system, and the apparatus for measurement of electrical energy have been described previously [6]. 


\section{Procedure}

In order to obtain a sufficient rate of reaction it was necessary to increase the surface area of the titanium by cutting the sample $(0.2$ to $0.3 \mathrm{~g})$ into small pieces; a carefully cleaned bolt-cutter was used for this purpose. The sample was placed in the center of the heated portion of the vessel between plugs of glass wool. The vessel was then assembled and placed in the calorimeter together with $4,618 \mathrm{~g}$ of water. Moisture and oxygen were removed from the vessel by evacuation followed by flushing with purified helium.

The calorimeter temperature observations were divided into three parts: A 50-min reaction period, and two 20 -min rating periods immediately preceding and following the reaction period [7]. Calorimeter temperatures were observed at 2-min intervals during the rating periods and at 1 -min intervals during the reaction period.

A mixture of bromine vapor and helium was introduced into the vessel at the start of the reaction period by bubbling helium through the bromine container. Two minutes later the vessel was heated electrically to $500^{\circ} \mathrm{C}$ and held at this temperature until the desired temperature rise of the calorimeter $\left(1.5^{\circ}\right.$ to $\left.2.0^{\circ} \mathrm{C}\right)$ was obtained. The electric current was then interrupted, the bromine container bypassed, and the flow of helium through the vessel continued for about $20 \mathrm{~min}$. The helium flow was then stopped and an additional $10 \mathrm{~min}$ was allowed for thermal equilibrium to be established.

The rate of flow of helium was measured by means of a calibrated capillary flowmeter; the total quantity of helium was calculated from observations of the rate and time. The total quantity of bromine used was determined by weighing the bromine container before and after each experiment; the excess bromine was taken as the difference between the total quantity and the stoichiometric quantity required for bromination of the sample. The temperatures of the helium and bromine entering the calorimeter were assumed to be the same as that of the calorimeter jacket through which they passed. These data were required only for the small gas heat capacity correction, where an error of 10 percent would affect the results by only 0.01 percent.

The quantity of reaction was determined from the mass of sample, since the reaction was complete in all cases. The contents of the trap were analyzed for titanium in order to correct the results for the heat of sublimation of a portion of the titanium tetrabromide. The solid titanium tetrabromide was dissolved in a dilute sulfuric acid solution and the amount of titanium determined gravimetrically as the dioxide [8]. This analysis (accurate to about $0.2 \%$ ) provided a check on the determination of the quantity of reaction.

The calorimetric system was calibrated by performing separate experiments in the same manner except that the titanium and bromine were omitted. In one series of experiments the quantity of electrical energy required to produce a certain temperature rise is determined; in a second series this temperature rise is duplicated but a substantial amount of the required energy is derived from the chemical reaction. In this way the energy associated with a given quantity of chemical reaction is compared directly with an equal quantity of electrical energy as measured in terms of calibrated standards.

\section{Results and Calculations}

The results of the electrical energy calibration experiments are given in table 1 , where $E$ is the electrical energy added to the system, $q_{g}$ is a correction for the heat carried into the system by the helium, $\Delta R c$ is the corrected temperature rise [7], $\Delta e_{1}$ is a correction for the heat capacity of the glass wool, and $E_{s}$ is the electrical energy equivalent of the standard calorimetric system. The system was the same in each case except for differences in the quantity of glass wool.

TABLE 1. Results of the electrical calibration experiments

\begin{tabular}{|c|c|c|c|c|c|}
\hline $\begin{array}{l}\text { Experiment } \\
\text { number }\end{array}$ & $E$ & $q_{g}$ & $\Delta R c$ & $\Delta e_{1}$ & $E_{s}$ \\
\hline $\begin{array}{l}1 \\
2 \\
3 \\
4 \\
5\end{array}$ & $\begin{array}{cc}j & \\
32278 & 6 \\
39253 & 5 \\
31296 & 0 \\
29594 & 1 \\
31288 & 2\end{array}$ & $\begin{array}{ll} & j \\
3.1 \\
3.8 \\
3 & 4 \\
2 & 2 \\
2.5 & \end{array}$ & $\begin{array}{c}\text { Ohm } \\
0.161117 \\
.195939 \\
.156166 \\
.147643 \\
.156234\end{array}$ & $\begin{array}{l}j / \text { ohm } \\
3.6 \\
3.6 \\
8.1 \\
8.1 \\
0\end{array}$ & $\begin{array}{c}\text { j/ohm } \\
200358.2 \\
200351.1 \\
200415.8 \\
200450.4 \\
200281.1\end{array}$ \\
\hline $\begin{array}{r}6 \\
7 \\
8 \\
9 \\
10\end{array}$ & $\begin{array}{l}36222.3 \\
32135.9 \\
35748.8 \\
27322.8 \\
27373.4\end{array}$ & $\begin{array}{ll}3 . & 4 \\
2 & 6 \\
2 . & 9 \\
2 . & \\
2 . & \end{array}$ & $\begin{array}{l}.180851 \\
.160385 \\
.178405 \\
.136369 \\
.136631\end{array}$ & $\begin{array}{l}0 \\
0 \\
0 \\
0 \\
0\end{array}$ & $\begin{array}{l}200306.9 \\
200383.4 \\
200396.3 \\
200376.9 \\
200360.8\end{array}$ \\
\hline \multicolumn{5}{|c|}{$\begin{array}{l}\text { Mean } \\
\text { Standard deviation of mean }\end{array}$} & $\begin{array}{l}200368.1 \\
\pm 15.6\end{array}$ \\
\hline
\end{tabular}

The results of the calorimetric experiments are given in table 2 , where $\Delta e_{2}$ is the deviation of the actual system from the standard calibrated system, $q$ is the total energy absorbed by the calorimeter, $q_{0}$ is a correction to $25^{\circ} \mathrm{C}$ for the reactants, products, and the helium, and $q_{s}$ is a correction for the quantity of titanium tetrabromide sublimed during the experiment. The quantity $q$ is obtained by the relationship:

$$
q=\Delta R c\left(E_{s}+\Delta e_{2}\right) .
$$

The heat of reaction is obtained by the relationship:

$$
-\Delta H=\frac{E-q+q_{g}-q_{s}}{\text { moles 'li }}
$$

For these calculations the density of titanium was taken as $4.50 \mathrm{~g} / \mathrm{cm}^{3}$ from the data of Fast [9]. The heat capacities of titanium, bromine, and helium were taken as $6.01,8.60$, and $4.97 \mathrm{cal} / \mathrm{deg}$ mole respectively, from the Selected Values of Chemical Thermodynamic Properties by Rossini et al. [3]. The heat capacity of titanium tetrabromide was taken as 28.93 cal/deg mole from the data of Hall and Blocher [10]. The heat of sublimation of titanium tetrabromide was calculated as $14.9 \mathrm{kcal} /$ mole from the vapor pressure 
TABLE 2. Results of the calorimetric experiments on the reaction of bromine with titanium

\begin{tabular}{|c|c|c|c|c|c|c|c|c|}
\hline $\begin{array}{l}\text { Ex- } \\
\text { peri- } \\
\text { ment } \\
\text { num- } \\
\text { ber }\end{array}$ & $\Delta R c$ & $\Delta e_{2}$ & $q$ & $E$ & $q_{g}$ & $q_{s}$ & Ti & $-\Delta H\left(25^{\circ} \mathrm{C}\right)$ \\
\hline $\begin{array}{l}1 \\
2 \\
3 \\
4 \\
5\end{array}$ & $\begin{array}{c}\text { Ohm } \\
0.131011 \\
.146616 \\
.132007 \\
.128886 \\
.149331\end{array}$ & $\begin{array}{c}\text { j/ohm } \\
9.8 \\
5.6 \\
6.7 \\
5.0 \\
5.6\end{array}$ & $\begin{array}{c}j \\
26251.7 \\
29378.0 \\
26450.9 \\
25825.3 \\
29918.0\end{array}$ & $\begin{array}{c}j \\
23322.1 \\
26099.9 \\
23271.5 \\
23462.0 \\
26602.1\end{array}$ & $\begin{array}{c}j \\
1.3 \\
2.1 \\
2.1 \\
2.4 \\
2.5\end{array}$ & $\begin{array}{c}j \\
0.2 \\
2.1 \\
2.1 \\
2.2 \\
1.8\end{array}$ & $\begin{array}{c}\text { Moles } \\
0.0043582 \\
.0048326 \\
.0046499 \\
.0035004 \\
.0049338\end{array}$ & $\begin{array}{c}\mathrm{kj} / \text { mole } \\
671.95 \\
678.33 \\
683.76 \\
675.09 \\
671.94\end{array}$ \\
\hline $\begin{array}{l}6 \\
7 \\
8\end{array}$ & $\begin{array}{l}.166368 \\
.205665 \\
.197521\end{array}$ & $\begin{array}{r}3.2 \\
9.4 \\
10.4\end{array}$ & $\begin{array}{l}33335.4 \\
41210.6 \\
39579.0\end{array}$ & $\begin{array}{l}30075.1 \\
37587.9 \\
36071.4\end{array}$ & $\begin{array}{l}3.9 \\
5.6 \\
4.8\end{array}$ & $\begin{array}{l}1.9 \\
2.0 \\
1.9\end{array}$ & $\begin{array}{l}.0048537 \\
.0052823 \\
.0050958\end{array}$ & $\begin{array}{l}671.30 \\
685.14 \\
687.76\end{array}$ \\
\hline \multicolumn{8}{|c|}{$\begin{array}{l}\text { Mean } \\
\text { Standard deviation of the mean. }\end{array}$} & $\begin{array}{l}678.16 \\
\pm 234\end{array}$ \\
\hline
\end{tabular}

data of Seki [11]. All calculations were based upon the 1956 table of International Atomic Weights [12] For conversion to the conventional thermochemical calorie the following relationship was used:

$$
1 \mathrm{cal}=4.1840 \mathrm{j} \text {. }
$$

The results given in table 2 correspond to the following process:

$$
\begin{aligned}
\mathrm{Ti}(\mathrm{c})+2 \mathrm{Br}_{2}(\mathrm{~g}) & =\mathrm{TiBr}_{4}(\mathrm{c}) \\
\Delta \mathrm{Hf}^{\circ}\left(25^{\circ} \mathrm{C}\right) & =-678.16 \pm 4.60 \mathrm{kj} / \mathrm{mole} \\
& =-162.08 \pm 1.10 \mathrm{kcal} / \mathrm{mole},
\end{aligned}
$$

If this value is combined with the heat of vaporization of bromine at $25^{\circ} \mathrm{C}, 7.34 \mathrm{kcal} /$ mole [3], the following standard heat of formation is obtained:

$$
\begin{aligned}
\mathrm{Ti}(\mathrm{c})+2 \mathrm{Br}_{2}(\mathrm{liq}) & =\mathrm{TiBr}_{4}(\mathrm{c}) \\
\Delta \mathrm{Hf}^{\circ}\left(25^{\circ} \mathrm{C}\right) & =-616.72 \pm 4.60 \mathrm{kj} / \text { mole } \\
& =-147.40 \pm 1.10 \mathrm{kcal} / \text { mole }
\end{aligned}
$$

The corresponding heats of formation obtained from the preliminary experiments on sponge titanium and commercial titanium sheet are -146.9 and $-147.8 \mathrm{kcal} / \mathrm{mole}$, respectively.

The stated uncertainty intervals are estimated over-all uncertainties, obtained by combining twice the standard deviation of the mean of the calibration and reaction experiments with reasonable estimates of all other known sources of error.

\section{Discussion}

A very slight amount of insoluble residue remained in the vessel after solution of the tetrabromide. This residue could not be weighed accurately because it could not be separated from the glass wool. Approximate measurements indicated that the residue weighed less than $1 \mathrm{mg}$ and it was assumed to be titanium dioxide. This quantity of material would account for approximately 0.1 percent of the original sample and would affect the heat of formation by only 0.04 percent.

The presence of 0.22 percent of chlorine in the bromine would be expected to introduce another error of approximately the same magnitude. However, no evidence was found for the presence of the tetrachloride among the reaction products. In any event, these errors are well within the uncertainty assigned to the heat of formation.

Since the completion of this work there have been two independent determinations of the heat of formation of $\mathrm{TiBr}_{4}$. Gross, Hayman, and Levi [13] measured the heat of reaction of titanium with liquid bromine and obtained $-148.1 \pm 0.25 \mathrm{kcal} / \mathrm{mole}$ for the standard heat of formation. Schläfer and Schmidtke [14] made an independent determination by the same general method and obtained $-147.87 \pm 0.04 \mathrm{kcal} /$ mole for the heat of formation. Both of these values agree with the results obtained in this investigation within the assigned uncertainties.

\section{References}

[1] L. Brewer, L. A. Bromley, P. W. Gilles, and N. L. Lofgren, Chemistry and metallurgy of miscellaneous materials, Thermodynamies, L. L. Quill, Ed. (McGrawHill Book Company, Inc., New York, N. Y., 1950).

[2] F. R. Bichowsky and F. D. Rossini, Thermochemistry of the chemical substances (Reinhold Publishing Corp., New York, N. Y., 1936).

[3] F. D. Rossini, D. D. Wagman, W. H. Evans, S. Levine, and I. Jaffe, Selected values of chemical thermodynamic properties, NBS Circ. 500 (U. S. Government Printing Office, Washington 25, D. C., 1952).

[4] W. H. Johnson, R. A. Nelson, and E. J. Prosen, J. Research NBS, 62, 49 (1959) RP2928.

[5] E. J. Prosen, W. H. Johnson, and F. Y. Pergiel, J. Research NBS, 61, 247 (1958) RP2901.

[6] E. J. Prosen, W. H. Johnson, and F. Y. Pergiel, J. Research NBS, 62, 43 (1959) RP2927.

[7] J. R. Eckman and F. D. Rossini, BS J. Research 6, 597 (1931) RP111.

[8] W. F. Hillebrand, G. E. F. Lundell, H. A. Bright, and J. I. Hoffman, Applied inorganic analysis, 2d ed. (John Wiley \& Sons, Inc., New York, N Y., 1953).

[9] J. D. Fast, Z. anorg. u. allgem. Chem. 241, 42 (1939).

[10] E. Hall and J. M. Blocher, Jr., J. Electrochem. Soc. 105, 40 (1958)

[11] S. Seki, J. Chem. Soc. Japan 62, 789 (1941).

[12] E. Wichers, J. Am. Chem. Soc. 78, 3238 (1956).

[13] P. Gross, C. Hayman, and D. L. Levi, Trans. Faraday Soc. 53, 1601 (1957).

[14] H. L. Schläfer and H. H. Schmidtke, Z. physik. Chem. (Frankfurt) [NF] 11, 297 (1957).

Washington, October 30, 1958 